\title{
THEORETICAL AND METHODICAL APPROACHES OF TRAINING SPECIALISTS FOR WORKING WITH CHILDREN WITH SPECIAL LIFETIME OPPORTUNITIES BY INCLUSIVE TOURISM
}

\author{
Mezhova L.A. ${ }^{1}$, Letin A.L. ${ }^{2}$ (Russian Federation) Email: Mezhova334@ scientifictext.ru
}

\author{
${ }^{I}$ Mezhova Lidia Alexandrovna - Candidate of Geographical Sciences, Associate Professor, Lecturer; \\ ${ }^{2}$ Letin Andrey Leonidovich - Candidate of Geographical Sciences, Lecturer, \\ DEPARTMENT OF GEOGRAPHY AND TOURISM, \\ VORONEZH STATE PEDAGOGICAL UNIVERSITY, \\ VORONEZH
}

\begin{abstract}
OBJ. Inclusive tourism actively socialises children into the environment. The development of the process of psychological and pedagogical support of their socialization is of a certain complexity. Inclusive tourism activities should be based on the diagnosis of children's diseases, on the structure and typology of the level of health status of children with OBV, combined with an assessment of the comfort of natural conditions of infrastructure and transport. A multifunctional technology of inclusive tourism in the system of basic general and supplementary education is presented. It includes principles, forms, methods, methods, competencies, milestones and implementation conditions, target groups, conditions and algorithm of inclusion.

Keywords: inclusive tourism, special opportunities for life, multifunctional technologies, inclusive tourism activities.

\section{ТЕОРЕТИЧЕСКИЕ И МЕТОДИЧЕСКИЕ ПОДХОДЫ К ПОДГОТОВКЕ СПЕЦИАЛИСТОВ ДЛЯ РАБОТЫ С ДЕТЬМИ С ОСОБЫМИ ВОЗМОЖНОСТЯМИ ЖИЗНЕДЕЯТЕЛЬНОСТИ СРЕДСТВАМИ ИНКЛЮЗИВНОГО ТУРИЗМА Межова Л.А. ${ }^{1}$, Летин А.Л.² (Российская Федерация)}

\author{
${ }^{I}$ Межова Лидия Александровна - кандидат географических наук, доцент, преподаватель; \\ ${ }^{2}$ Летин Андрей Леонидович - кандидат географических наук, преподаватель, \\ кафедра географии и туризма, \\ Воронежский государственный педагогический университет,
} 2. Воронеж
\end{abstract}

\begin{abstract}
Аннотация: инклюзивная деятельность формирует толерантное отношение к детям с ОВЖ. Инклюзивный туризм активно социализирует детей в окружаюшую среду. Определённую сложность имеет разработка процесса психолого-педагогического сопровождения их социализации. Инклюзивная туристическая деятельность должна опираться на диагностику заболеваний детей, на структуру и типологию уровня состояния здоровья детей с ОВЖ в сочетании с оченкой комфортности природных условий инфраструктуры и транспорта. Представлена полифункииональная технология инклюзивного туризма в системе основного общзего и дополнительного образования, включающая принципы, формы, методы, приемы, компетенции, основные этапь и условия реализации, целевые группь, условия и алгоритм инклюзии.
\end{abstract}

Ключевые слова: инклюзивный туризм, особые возможности жизнедеятельности, полифункииональные технологии, инклюзивная туристическая деятельность.

Особый интерес сегодня вызывает инклюзивное образование, направленное на детей с особыми познавательными потребностями и включенных в общий образовательный процесс. В настоящее время среди основных направлений исследований отмечена огромная роль инклюзивного туризма в решении задач социализации и создания соответствующих условий, образа жизни и повышения уровни качества жизни детей с ограниченными возможностями жизнедеятельности в условиях общего образования [3, с. 242].

Научные исследования отражают смену парадигмы реабилитации через отказ от нормируемости в пользу индивидуального маршрута развития. Однако до сих пор недостаточно изучена комплексная подготовка специалистов для работы с детьми различными отклонениями здоровья совместно со здоровыми.

Анализ направлений теоретических исследований и методологических подходов по исследуемой проблеме позволил выявить совокупность противоречий, между потребностями профессиональной педагогической сферы в специалистах, способных к реализации инклюзивно-туристских программ с обучающимися, и недостаточной разработанностью педагогических технологий профессионального 
образования будущих педагогов в системе дополнительного образования, обеспечивающих туристскую подготовку как форму инклюзии обучающихся с ограниченными возможностями в общем образовательном процессе. В связи с актуальностью проблемы эффективности процесса инклюзии детей с ограниченными возможностями остро стоит необходимость методического разнообразия подходов в ее реализации.

Цель исследования является изучение эффективности методических подходов и их реализации в процессе инклюзии детей с ограниченными возможностями здоровья при реализации инклюзивнотуристских программ

Материалы и методы исследования. На современном этапе в образовании отмечается неполное соответствие между профессионально-ориентированной средой, в которой осуществляется подготовка будущего специалиста, и требованиями профессиональной практической деятельности. Как показывает практика, немногие из учителей обладают готовностью к организации и проведению школьных экскурсий, походов и туров, летних туристических лагерей и других конкретных форм туристской деятельности с целью инклюзии обучающихся с ограниченными возможностями жизнедеятельности. Во многом это объясняется тем, что студенты в процессе учебы не получают достаточного опыта для выполнения функции организаторов школьного туризма, включая инклюзивный туризм. Передача студентам такого специфичного опыта - залог расширения их профессиональных компетенций в области социализации детей.

Необходимость разрешения указанных противоречий определяет актуальность проблемы исследования, связанную с теоретико-методологическим и практическим обоснованием подготовки специалистов в области инклюзивного туризма для детей с ограниченными возможностями жизнедеятельности. Для разрешения теоретических и практических противоречий использовались следующие методы: анализа психолого-педагогических и методических литературных источников, методы математической статистики, проектирование и моделирование технологии туристической реабилитации; эмпирические методы (наблюдения, беседа, анкетирование, тестирование), психологопедагогические методики оценки качеств личности, биометрические методики состояния здоровья, обобщение практического опыта, педагогический эксперимент (констатирующий, формирующий и контрольные этапы).

Методологические аспекты проблемы развития инклюзивного туризма для детей с ОВЖ определили многообразие подходов по оценке уровня готовности студентов к формированию туристскореабилитационной культуры для работы с детьми с ОВЖ.

Основные методики развития социальной компетентности представлены в таблице 1.

Таблииа 1.Основные методики диагностики развития соичальной компетентности студентов [1, с. 72-74]

\begin{tabular}{|c|c|c|}
\hline Критерии & Показатели & Диагностические методики \\
\hline $\begin{array}{c}\text { Мотивационно- } \\
\text { ценностный }\end{array}$ & $\begin{array}{c}\text { Направленность в общении и } \\
\text { профессиональной } \\
\text { деятельности } \\
\text { Социальные установки } \\
\text { личности }\end{array}$ & $\begin{array}{c}\text { Методика определения направленности личности в } \\
\text { общении (В. Смекал, М. Кучер), } \\
\text { Методика диагностики межличностных отношений } \\
\text { (А.А. Руковишников). } \\
\text { Опросник Херманса (1971) }\end{array}$ \\
\hline Поведенческий & $\begin{array}{c}\text { Адаптивные способности } \\
\text { студентов }\end{array}$ & $\begin{array}{c}\text { Методика диагностики коммуникативных умений и } \\
\text { навыков (В.М. Снетков) } \\
\text { Метод последовательной динамической оценки } \\
\text { (Шведин Б.Я.) }\end{array}$ \\
\hline Коммуникативные & $\begin{array}{c}\text { Коммуникативные и } \\
\text { организаторские склонности }\end{array}$ & $\begin{array}{c}\text { КОС (Синявский В.В., Федорошин В.А.) } \\
\text { ОСУД (Кудряшова Л.Д.) } \\
\text { Оценка удовлетворенности от принадлежности к } \\
\text { группе (Головановский А.Я.) } \\
\text { Методика диагностики организаторских } \\
\text { способностей (Л.И. Урманский). } \\
\end{array}$ \\
\hline Личностные & $\begin{array}{l}\text { Качества личности, уровень } \\
\text { самооценка }\end{array}$ & $\begin{array}{c}\text { Методика управляемой проекции (Столин В.В.), } \\
\text { Метод субъективного шкалирования (Р. Вудворс, Г. } \\
\text { Шлосберг), Методика оценки уверенности к себе } \\
(1990) \\
\end{array}$ \\
\hline $\begin{array}{c}\text { Межличностные } \\
\text { отношения }\end{array}$ & Межличностные отношения & $\begin{array}{c}\text { МДСВ (Томас К.Н.), методика межличностной } \\
\text { диагностики (Т. Лари, Лафорж, Р. Сакзек, 1978), } \\
\text { социометрия (Дж. Морено, 1951) }\end{array}$ \\
\hline
\end{tabular}

Результаты исследования и их обсуждение. Для оценки эффективности полифункциональных технологий необходимо для будущего учителя в вузе определить: его готовность к участию в инновационных процессах; умение работать в инновационном образовательном пространстве; наличие у 
будущего педагога эрудиции, культуры, педагогического такта, оптимизма, знание психологии для детей с ОВЖ, умение создавать комфортный психологический климат для детей с различными уровнями здоровья и интеллектуального уровня; работать с новейшими техническими средствами адаптации детей с окружающей средой и системами дистанционного контроля для работы с детьми с ОВЖ в группах со здоровыми; расширение у будущего учителя психолого-педагогических научных компетенций.

Системный подход позволяет интегрировать содержательную компоненту формируемых дифференцированных компетенций различного рода в связи со спецификой целевых групп и специальными характеристиками процесса реабилитации. Деятельностный подход (В.И. Загвязинский, А.Н. Леонтьев, С.Л. Рубинштейн и др.) предполагает создание условий для реализации индивидуальных личностных качеств путем использования методологического инструментария в процессе постоянно усложняющейся учебнопредметной деятельности студентов, предусматривающей коммуникативное взаимодействие и адекватное использование социальных ролей в групповых технологиях. Личностно-ориентированный подход (Э.Ф. Зеер, Е.В. Бондаревская, И.С. Якиманская и др.) не только определяет ценностную ориентацию во взаимодействии с каждым субъектом педагогического взаимодействия, но создает предпосылки личностного развития и карьерной реализации профессионала, что выражается в процессуальном контроле личностных достижений и навыках социальных коммуникаций [2, с. 15-35, 3, с. 241-246].

Специально-психологический цикл предназначен для реализации образовательных потребностей, связанных с особенностями состояния здоровья детей, специфическими условиями использования туристических технологий для реабилитации их физиологического состояния и коррекции психологических особенностей, формирования саногенного типа мышления и ориентацию на здоровьесберегающие технологии жизнедеятельности. В него включены в составе теоретического блока педагогические условия для применения совокупности методик диагностики эффективности объективных воздействий и субъективных взаимодействий, когнитивные компоненты психологической компетенции, элементы симптоматики, валеологии, элементарной терапевтики, клинической и педиатрической психологии. Методический модуль включает проектные технологии для реализации креативного мышления как способа формирования нового типа поведения детей в условиях ограниченной жизнедеятельности, формирования саногенного типа мышления, оценки эффективности реализации предложенной модели. Критериально-оценочный модуль направлен на перевод теоретических знаний и практических умений в навык использования групповых технологий психолого-педагогического воздействия с последующим формированием у детей устойчивого процессуального контроля индивидуальных достижений для выработки адекватной самооценки и позитивного взгляда на свое место в социальных группах. Цель состоит в формировании специальных компетенций по реализации полифункциональной технологии инклюзивного туризма с использованием диагностического комплекса субъект-объективной оценки социализации и процессуального контроль индивидуальных достижений детей с ОВЖ.

Особенностью предлагаемой модели является использование психолого-педагогических средств при применении форм инклюзивного туризма для формирования различных компетенций в системе профессиональной подготовки студентов в вузе благодаря поэтапному алгоритму усвоению теоретических знаний в трех основных учебных циклах и приобретению необходимых коммуникативных компетенций и ценностных ориентаций в процессе формирования социально-педагогической среды в туристских технологиях.

В результате опытно-экспериментальной деятельности проведены диагностические срезы: входной пропедевтический и итоговый во всех группах, принимавших участие в эксперименте. Для диагностики провели экспериментальные исследования с группой детей с ОВЖ, используя инклюзивную туристическую деятельность, на основе которой определена готовность студентов к реализации полифункциональных технологий

Уровень подготовленности студентов по степени сформированности компетентности использования полифункциональных технологий для социализации детей с ОВЖ в смешенных группах определялась по комплексной программе. В состав программы входили несколько групп методов психолого-педагогического исследования, которые обеспечивали взаимную верификацию показателей и степень достоверности результатов тестирования, наблюдения и методов социометрии. Используемые тестовые методики позволили измерить уровни коммуникативной компетентности, а также межличностные отношения и адаптивные способности личности (рис. 1, 2). 


\section{Уровень социализации (экспериментальная группа)}

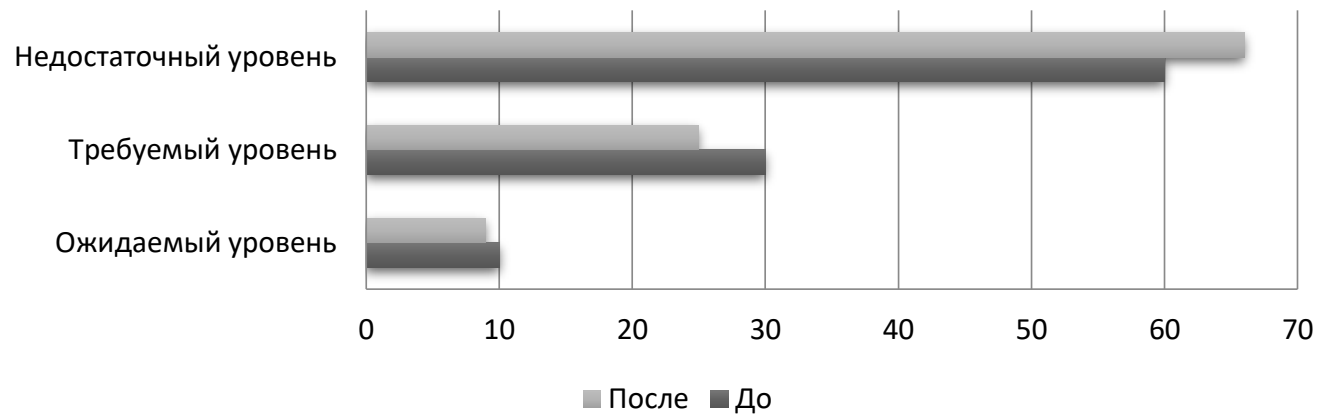

Рис. 1. Динамика уровня сочиилизации детей с ОВЖ в контрольной группе

\section{Уровень социализации (экспериментальная группа)}

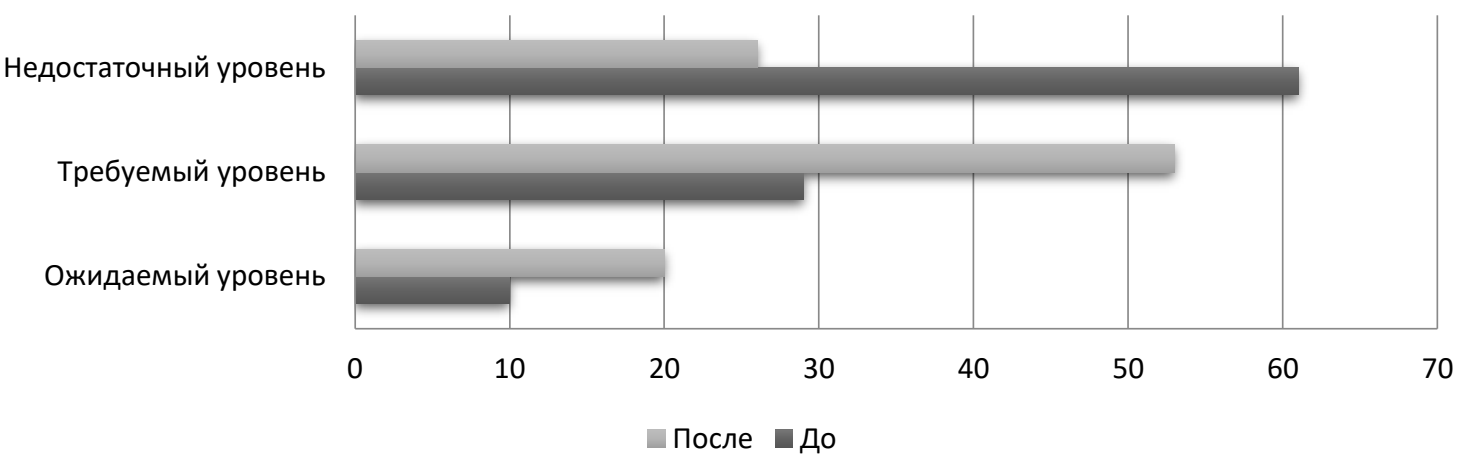

Рис. 2. Динамика уровня социализации детей с ОВЖ в экспериментальной группе

Результаты эксперимента показывают (рис. 3, 4), что количество детей с ОВЖ, имеющих нормальную и допустимую самооценку (экспериментальная группа) за время увеличилось на 29\% за счет группы с низкой самооценкой и составило 59\%. Сравнивая с контрольной группой следует отметить естественный процесс нормализации происходит в значительной степени при целенаправленном воздействии через создания педагогической среды.

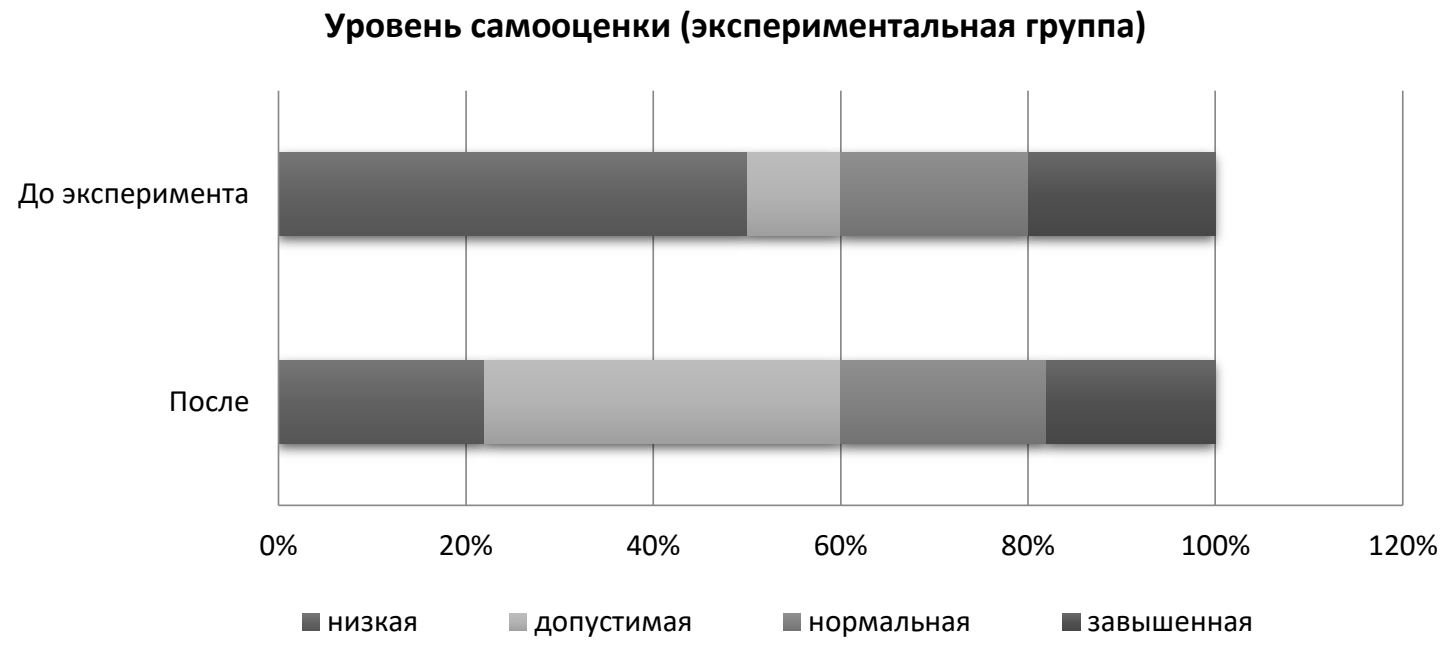

Рис. 3. Динамика уровня самооченки детей с ОВЖ в экспериментальной группе 


\section{Уровень самооценки (контрольная группа)}

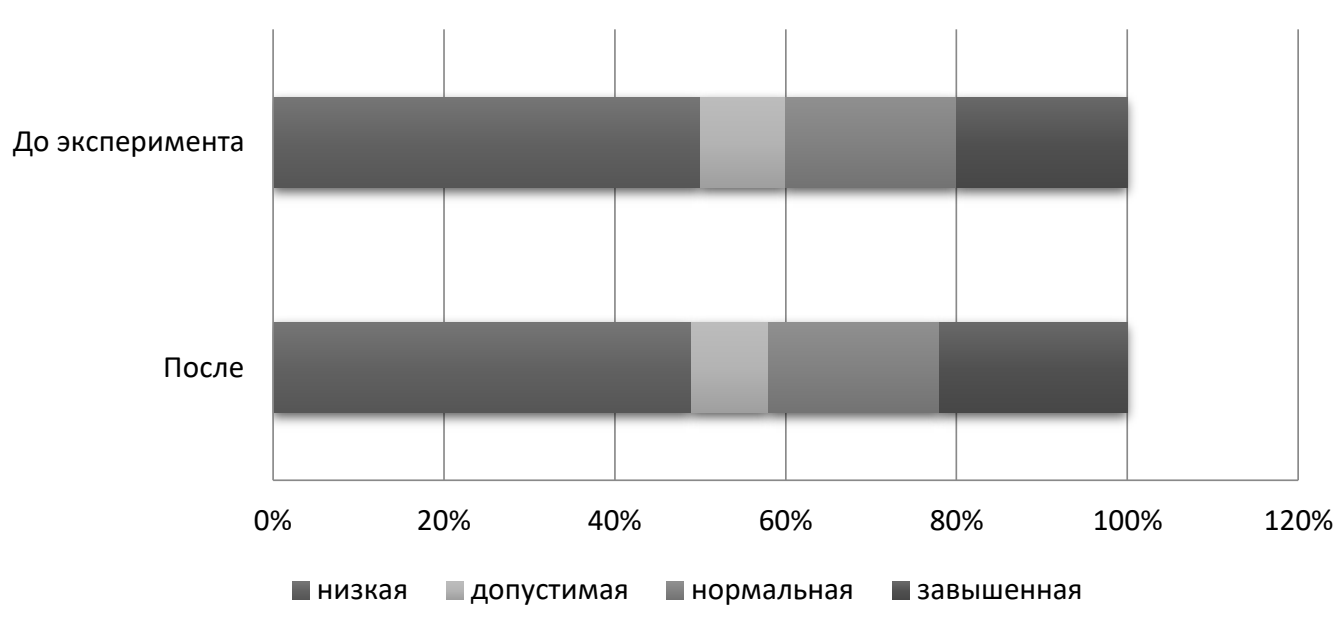

Рис. 4. Динамика уровня самооиенки детей с ОВЖ в контрольной группе

Анализ рейтингового уровня детей с ОВЖ и его динамики показывает переход 10\% детей в более высокий ранг, одновременно отмечен значительный рост внутри их количества детей с повышением рейтинга при незначительном снижении, тогда как контрольная группа свидетельствует о стабильном характере социальной роли в классном коллективе и уровня достижений с незначительным уровнем разнонаправленной динамики.

Достоверность результатов экспериментального исследования подтверждена результатами статистического анализа с использованием t-критерия Стьюдента и $\chi^{2}$ - критерия Пирсона. В контрольной группе статистически достоверных различий в экспериментальных данных до и после проводимой

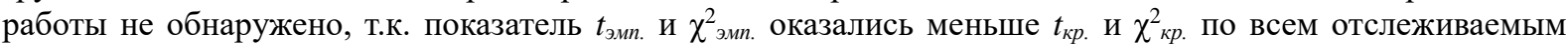
показателям.

В результате реализации полифункциональной технологии инклюзивного туризма в экспериментальной группе выявлены статистически достоверные отличия до и после проводимого эксперимента по всем отслеживаемым показателям: $t_{\text {эмn. }}>t_{k p}$. у уровнем статистической значимости $0,01 \% ; \chi^{2}{ }_{\text {эnп. }}^{>} \chi^{2}{ }_{\kappa p}$. уровнем статистической значимости $0,001 \%$ (за исключением показателей инновационной компоненты, где по $\chi^{2}$-ккритерию Пирсона, $\chi^{2}$ эмп. $<\chi_{\kappa p}^{2}$. с уровнем статистической значимости 0,05), что с достаточно высокой степенью достоверности свидетельствует повышение уровня сформированности исследуемых показателей - уровня самооценки и социализации детей ОВЖ, компетентности студентов.

Итоги формирующего эксперимента демонстрируют эффективность реализации разработанной нами и апробированной на определенном контингенте детей ОВЖ технологии психолого-педагогической и социальной реабилитации способствовали раскрытию индивидуального потенциала за счет повышения самооценки и веры в свои силы. Технология использования диагностического комплекса субъективной оценки и объективной рейтинговой оценки методиками социометрии показала положительную динамику, проявившейся в улучшении всех исследуемых компонентов у подавляющего большинства детей экспериментальной группы, и с подавляющим превосходством над показателями контрольной группы.

Выводы. Анализ теоретических подходов к проблеме психолого-педагогической и физиологической реабилитации лиц с ОВЖ свидетельствует о многообразии подходов к инклюзивному туризму в России и за рубежом. Новые подходы к инклюзивной туристической деятельности начали развиваться в начале XXI века, которые развиваются на основе классификации направлений инклюзивного туризма в сочетании с типологии состояния здоровья детей с ОВЖ.

Новое интенсивно развивающееся направление инклюзивного туризма имеет значительные потенциальные возможности, но вместе с тем следует отметить, что не разработана специализированная система подготовки специалистов по инклюзивному туризму для различных типов организации дополнительного образования. Методические аспекты проблем инклюзивного туризма для лиц с ОВЖ позволили разработать и использовать полифункциональные технологии для подготовки специалистов к инклюзивной туристической деятельности. Предложенный алгоритм подготовки специалистов в области инклюзивного туризма позволяет формировать саногенный тип мышления для составления индивидуальных жизненных программ для детей с ОВЖ их социализации и нормализации уровня их самооценки. 


\section{Сиисок литературы / References}

1. Губин И.В. Деятельностный подход в подготовке специалистов по реабилитационному туризму / И.В. Губин, Л.А. Межова // Культура физическая и здоровье. № 4 (40). Воронеж, 2012. С. $72-74$.

2. Межова Л.А. Теория и практика развития регионального туризма: монография / Л.А. Межова, А.Л. Летин, Л.А. Луговская. Воронеж: Воронежский государственный педагогический университет, $2015.304 \mathrm{c}$.

3. Проблемы развития инклюзивного туризма: адаптация инвалидов / А.И. Сесёлкин, А.С. Махов, В.Д. Чепик // Ученые записки университета им. П.Ф. Лесгафта, 2015. № 11 (129). С. 241-246.

4. Конвенция о правах инвалидов. Принята резолюцией 61/106 Генеральной Ассамблеи ООН от 13 декабря 2006 года // Конвенции и соглашения. [Электронный ресурс]. Режим доступа: http://www.un.org/ru/documents/decl_conv/conventions/disability.shtml/ (дата обращения: 29.11.2017). 